\title{
Modelling and Optimization of Power Consumption in Wireless Access Networks
}

\author{
Margot Deruyck, Emmeric Tanghe, Wout Joseph and Luc Martens \\ Ghent University - IBBT, Departement of Information Technology (INTEC) \\ Gaston Crommenlaan 8, Bus 201, 9050 Ghent, Belgium \\ email: margot.deruyck@intec.ugent.be \\ website: www.wica.intec.ugent.be
}

\begin{abstract}
The power consumption of wireless access networks will become an important issue in the coming years. In this paper, the power consumption of base stations for mobile WiMAX, fixed WiMAX, UMTS, HSPA, and LTE is modelled and related to the coverage. A new metric, the power consumption per covered area $P C_{\text {area }}$, is introduced, to compare the energy efficiency of the considered technologies for a range of bit rates. Assuming the model parameters are correct, the conclusions are then as follows. For a $5 \mathrm{MHz}$ channel, UMTS is the most energy-efficient technology until a bit rate of 2.8 Mbps, LTE between 2.8 Mbps and 8.2 Mbps, fixed WiMAX between $8.2 \mathrm{Mbps}$ and $13.8 \mathrm{Mbps}$ and finally mobile WiMAX for bit rates higher than $13.8 \mathrm{Mbps}$. Furthermore, the influence of MIMO is investigated.
\end{abstract}

For a 2x2 MIMO system, $P C_{\text {area }}$ decreases by $36 \%$ for mobile WiMAX and by $23 \%$ for HSPA and LTE compared to the SISO system, resulting in a higher energy efficiency.

The power consumption model for base stations is used in the deployment tool GRAND (Green Radio Access Network Design) for green wireless access networks. GRAND uses a genetic based algorithm and is applied on an actual case for the Brussels Capital Region, showing the possibilities of energy-efficient planning.

Keywords: power consumption, base station, coverage, access networks, MIMO 


\section{Introduction}

Recent studies have shown that the power consumption of ICT is approximately $4 \%$ of the annual energy production [1]. More importantly, this number is expected to grow drastically in the coming years. The Internet traffic has a compound annual growth rate of $40 \%$ i.e., doubling every two years [2]. Moreover, the Wireless World Research Forum (WWRF) has a vision of 7 trillion wireless devices serving 7 billion users by 2017 [3]. This indicates that the power consumption of wireless access networks is going to become an important issue in the coming years.

Earlier work showed that the radio access network is a large contributor to $\mathrm{CO}_{2}$ emissions $[1,4,5]$. Particulary, the base stations are responsible for roughly two-thirds of the total $\mathrm{CO}_{2}$ emissions of these radio access networks [4]. NTT DoCoMo states that the daily energy consumption per consumer is $0.83 \mathrm{Wh}$ for a terminal and $120 \mathrm{Wh}$ for the mobile network which is a consumption ratio of terminal versus network of about 1:150 [5]. The energy consumption of terminals is thus negligible with respect to the energy consumption of the networks. Therefore, it is clear that we should focus on the base stations in the wireless access networks in order to reduce the energy consumption, as the terminals are already optimized in terms of energy consumption because they are powered by batteries.

The objective of this paper is to model the power consumption of base stations of various wireless technologies and compare the energy efficiency of the considered technologies for various physical bit rates versus the coverage range. In order to determine the energy efficiency of the considered technologies, a new metric, namely the power consumption per covered area, is defined. The deployment tool GRAND (Green Radio Access Network Design) models and optimizes the power consumption of a network in a realistic area.

The outline of the paper is as follows. Section 2 discusses some related work. In Section 3, a short overview of the considered technologies is given. In Section 4, the power consumption of a base station is modelled and related to the coverage. Section 5 discusses our deployment tool GRAND for green wireless access networks. Section 6 gives some results for the considered technologies obtained with the model from Section 4. Section 7 shows some results for the considered technologies and the actual case of Brussels Capital Region obtained with our tool GRAND. In Section 8, the final conclusions are given. 


\section{Related work}

As the power consumption and energy efficiency of telecommunications networks become more and more important, the topic starts to appear in literature. In [6], a good overview is given of the power consumption in the different parts of a network. Furthermore, a comparison is made between wireless and wired access networks. Specifically for wireless access networks, most studies focus on energy-efficient deployments of wireless access networks such as $[7,8,9,10]$. These studies try to reduce the number of base stations in the network by switching them off during periods of low traffic which is a very promising method for energy savings. These studies in combination with a realistic power consumption model for base stations will enable to quantify the actual power savings in the network. However, very few work has been done on power consumption models for base stations. A simple model is proposed in [11] where the power consumption is characterized by three parameters: the transmission power, the efficiency of the transmission chain and a parameter that contains all the other power needed. It is assumed that the base station operates at full traffic load. [12] defines a power consumption model for both macro sites and micro sites. Based on these power consumption models, a network is deployed by mixing macro and micro sites. [13] defines the power consumption of the base station as a function of the load on the base station. The power consumption that scales with the transmit power of the antenna like in [12] is not taken into account in this model. A last model is a $\mathrm{CO}_{2}$ emission model proposed by [14]. This model focusses on DVB (Digital Video Broadcast) networks and the power consumption is estimated based on its efficiency (i.e., the ratio of the output power of the base station to the input power of the base station). The mentioned studies have two minor points in common. Firstly, the power consumption of different components is combined into two or three parameters. This makes it very difficult to investigate the influence of the different components of the base stations on the total power consumption, as well as the influence of possible dependencies between the components. Secondly, each study focusses only on one wireless technology while our work shows that for the considered case and for the assumed model parameter values, distinct differences in energy efficiency can be noticed between the considered technologies. 


\section{Technologies}

The power consumption of outdoor base stations is investigated for five different wireless technologies: mobile WiMAX (Worldwide Interoperability for Microwave Access) [15], fixed WiMAX [16], UMTS (Universal Mobile Telecommunications System) [17], HSPA (High Speed Packet Access) [18] and LTE (Long Term Evolution) [19]. A short description of each technology is given in this section.

WiMAX is a wireless technology for broadband communication based on the IEEE 802.16 standard [15]. For fixed WiMAX, the 802.16-2004 interface is analysed, operating in the $2-11 \mathrm{GHz}$ band. This interface supports fixed, nomadic and portable services, making it a good alternative for broadband fixed wireline services. Mobile WiMAX (the IEEE 802.16e interface) [15] is developed for mobile wireless applications and operates in the $2-6 \mathrm{GHz}$ band. Fixed WiMAX uses OFDMA (Orthogonal Frequency Division Multiple Access) as multiple access technique, while mobile WiMAX uses the novel SOFDMA (Scalable Orthogonal Frequency Division Multiple Access) technique. SOFDMA is derived from OFDMA and supports a wide range of bandwidths to flexibly address the need for various spectrum allocation and application requirements. The peak theoretical downlink data rate for mobile WiMAX is 46 Mbps.

UMTS is developed by ETSI (European Telecommunications Standardisation Institute) and operates in the $2.1 \mathrm{GHz}$ band [17]. UMTS has been specified as an integrated solution for mobile voice and data. It offers mobile operators significant capacity and broadband capabilities to support more voice and data consumers, especially in urban centres. UMTS uses W-CDMA (Wideband Code Division Multiple Access) as multiple access technique and has a maximum bit rate of only $3 \mathrm{Mbps}$. The peak theoretical downlink data rate is increased to $14 \mathrm{Mbps}$ in HSPA which is the successor of the widely deployed UMTS and works also in the $2.1 \mathrm{GHz}$ band. HSPA promises higher data rates, increased cell and user throughput and reduced delay compared to UMTS [18]. Furthermore, it supports shared channel transmission. This means that the channelization codes and the transmission power in a cell are dynamically shared between users.

LTE is the newest wireless broadband technology [19]. In December 2009, world's first publicly available LTE-service was started in Scandinavia [20]. LTE is marketed as the fourth generation of radio technologies. It uses SOFDMA as multiple access technique and thus supports variable band- 
widths, just like mobile WiMAX supports scalability. LTE uses the $2.6 \mathrm{GHz}$ band. In the future, LTE may also use the $800 \mathrm{MHz}$ band (digital dividend frequencies). LTE promises downlink peak rates of at least $100 \mathrm{Mbps}$.

\section{Theoretical power consumption and coverage model for wireless access}

A model is developed to determine the power consumption of a base station [21]. Using this model, the base station's power consumption is then related to the base station's wireless coverage range. In this section, the model and the relation with the coverage are discussed in detail.

\subsection{Power consumption of a base station}

In a base station, we typically find several power consuming components. Fig. 1 gives an overview of these components [22, 23, 24]. The area covered by one base station is called a cell. Each cell is further divided in a number

of sectors. Each sector is covered by a sector antenna, which is a directional antenna with a sector-shaped radiation pattern. Some equipment is used per sector such as the digital signal processing (responsible for system processing and coding), the power amplifier, the transceiver (responsible for signal generation and receiving/sending of signals to the mobile stations) and the rectifier. The power consumption of these components should be multiplied with the number of supported sectors when determining the power consumption of the base station. In contrary to [25] and [26], it is assumed that the signal generator is part of the transceiver. This adaptation is based on the information retrieved from wireless operators. Furthermore, a base station contains equipment that is common for all sectors such as the air conditioning and the microwave link (responsible for communication with the backhaul network in case no fiber link is available). The division between the components per sector and the components common for all sectors is based on the information obtained from operators.

[Fig. 1 about here.]

The power consumption of each component is here assumed to be constant except for the air conditioning and the power amplifier. The power consumption of the air conditioning depends on the internal and ambient temperature of the base station cabinet (based on the information retrieved 
from datasheets of manufacturers [27]). We assumed an internal and ambient temperature of $25^{\circ} \mathrm{C}$. To model the power consumption of the power amplifier, we define the efficiency $\eta$ of the power amplifier. The efficiency $\eta$ of the power amplifier is the ratio of RF output power $P_{\text {out } / a m p}$ (in Watt) to the electrical input power $P_{e l / a m p}$ of the power amplifier (in Watt) [28]:

$$
\eta=\frac{P_{o u t / a m p}}{P_{\text {el/amp }}}
$$

The output power $P_{\text {out } / a m p}$ of the power amplifier is the input power $P_{T x}$ of the sector antenna. Based on $P_{T x}$ and eq. (1), the power consumption of the power amplifier is determined as follows:

$$
P_{e l / a m p}=\frac{P_{T x}}{\eta}
$$

Once the power consumption of each component is known, the power consumption $P_{e l}$ of the entire base station (in Watt) can be calculated:

$P_{\text {el }}=n_{\text {sector }} \cdot\left(n_{T x} \cdot\left(P_{\text {el/amp }}+P_{\text {el/trans }}\right)+P_{\text {el/proc }}+P_{\text {el/rect }}\right)+P_{\text {el } / \text { micro }}+P_{\text {el } / \text { airco }}$

with $n_{\text {sector }}$ the number of sectors in the cell, $P_{\text {el/amp }}, P_{\text {el/trans }}, P_{\text {el/proc }}, P_{\text {el/rect }}$, $P_{e l / m i c r o}$ and $P_{e l / a i r c o}$ are the power consumptions (in Watt) of respectively the power amplifier, the transceiver, the digital signal processing, the rectifier, the microwave link (if present), and the air conditioning. In case MIMO is used, the base station needs the same number of power amplifiers and the same number of transceivers as the number of transmitting antennas [29]. MIMO has also an influence on the digital signal processing which is, compared to the influence on the transceivers, negligible. To take the power consumption of this added equipment into account, the power consumption of the power amplifier and the transceiver is multiplied by the number of transmitting antennas $n_{T x}$ for one sector. Important to remark is that eq. (3) is valid when only one frequency is used per sector.

Table 1 summarizes the power consumption of the different components of a base station for the considered technologies. These values are retrieved from data sheets of various manufacturers of network equipment and from standards $[22,30,31,32,33,34,35]$. For the power amplifier, the maximum power consumption is indicated. The power consumption of the digital signal processing and transceiver are based on confidential data retrieved from an 
operator. Important to remark is that the results presented in this paper depend on the values listed in Table 1.

[Table 1 about here.]

The most important source of power consumption is the air conditioning. In contrary to [25], the same air conditioning is used for all technologies because the air conditioning is not technology-dependent and we want to make a fair comparison between the technologies. Also the rectifier is not technology-dependent. These assumptions are made based on the information retrieved from operators. The considered microwave links support all the considered technologies and the same thing is true for the digital signal processing, the transceiver and the power amplifier. The power amplifier can be used for all the considered technologies because it supports the frequency bands of each technology. Moreover, the range of RF output power of this power amplifier covers the needed input power of the antennas for each considered technology. The power amplifier for the extended configuration can also be used for all the considered technologies.

As a validation of our model, we compare the power consumption with available data and measurements. For a 3-sector base station with one antenna per sector, $P_{e l}$ of $1672.6 \mathrm{~W}$ is found with eq. (3) for UMTS, HSPA and LTE. In [22] and [24], $P_{e l}$ of $1700 \mathrm{~W}$ and $1500 \mathrm{~W}$, respectively, are found for the traditional $3 \mathrm{G}$ base station which is similar to the $P_{e l}$ obtained with our model. In [12], $P_{e l}$ for a 1-sector base station with one antenna is $783 \mathrm{~W}$. With our model, similarly, $P_{e l}=761 \mathrm{~W}$, is obtained. Furthermore, a good similarity between our $P_{e l}$ and confidential data from an operator about the power consumption of $3 \mathrm{G}$ base stations is obtained.

\subsection{Calculation of the coverage range $R$ of the base station}

Once the power consumption $P_{e l}$ of the base station is known, it is related to the wireless range $R$ covered by this base station. To this end, a link budget has to be determined. A link budget takes all the gains and the losses of the transmitter and the propagation through the medium to the receiver into account. Firstly, we need to calculate the maximum allowable path loss $P L_{\max }$ (in $\mathrm{dB}$ ) to which a transmitted signal can be subjected while still being detectable at the receiver. The path loss is the ratio of the transmitted

power to the received power of the signal [36]. It includes all of the possible 
elements of loss associated with interactions between the propagating wave and any objects between the transmit and receive antennas. To determine the maximum allowable path loss $P L_{\max }$, the gain and loss parameters of Table 2 are taken into account. These parameters are retrieved from specifications and/or are typical values proposed by the operators themselves. The typical values allow to make a fair comparison between the considered technologies.

[Table 2 about here.]

Some of these parameters need a short explanation. The fading margin accounts for temporal fading (due to e.g., varying weather conditions) and is determined based on the projected yearly availability of the system. The noise figure is a measure of degradation of the SNR caused by components in the radio frequency signal chain. The receiver SNR (Signal-to-Noise Ratio) determines the minimum required SNR at the receiver for a certain BER (Bit Error Rate). For mobile WiMAX, fixed WiMAX, HSPA, and LTE, Table 2 shows that the receiver SNR depends on the used modulation scheme and coding rate. Because UMTS uses only one modulation (i.e., QPSK in the downlink), the receiver SNR depends on the chosen services. In Table 2, the receiver SNR for only three out of five UMTS services is given. The other two services have the same bit rate (2 Mbps) as the PS (Packet Switch) 64 data service but they have a higher required receiver SNR. The PS 64 data service is here chosen because it is the most energy-efficient service that supports the 2 Mbps bit rate. Furthermore, because UMTS and HSPA use W-CDMA as multiple access technique, an extra gain needs to be taken into account. This gain is called the processing gain $P G$ (in $\mathrm{dB}$ ) and is defined as [37]:

$$
P G=-10 \cdot \log _{10}(S P)=-10 \cdot \log _{10}\left(\frac{C R}{S R}\right)
$$

with $S P$ the spreading factor which is the ratio of the chip rate $C R$ (in Mcps) to the symbol rate $S R$ (in Mbps). The processing gain is thus the ratio of the spread (RF) bandwidth to the unspread (baseband) bandwidth. Also the input power of the antenna for UMTS and HSPA needs to be scaled according to the control overhead, the target load, and the maximum number of users [38]:

$$
P_{T x}^{T C H}=\frac{(1-C L) \cdot P_{T x}}{T L \cdot N_{u s e r s}}
$$


with $P_{T x}^{T C H}$ the power reserved by the base station for the traffic channels. $C L$ is the control overhead, $T L$ the target load and $N_{\text {users }}$ the maximum number of users. $P_{T x}$ is used to determine the power consumption of the base station and $P_{T x}^{T C H}$ is used to determine the range of the UMTS and HSPA base stations (Table 2). For mobile WiMAX, fixed WiMAX , and LTE $P_{T x}$ in Table 2 is equal to $P_{T x}^{T C H}$ because an OFDMA based multiple access technology is used. Also, the user interference margin UIM (in $\mathrm{dB}$ ), needs to be taken into account when using UMTS and HSPA [38]:

$$
U I M=-10 \cdot \log _{10}(1-T L)
$$

with $T L$ the target load.

For mobile WiMAX, HSPA and LTE, an extra gain needs to be taken into account for the extended configuration (MIMO). In this paper, antenna diversity is used. This gain is called the MIMO gain $G_{M I M O}$. In contrary to [26] where the theoretical diversity gain was chosen [39], a more realistic gain of $3.5 \mathrm{~dB}$, as found in [40], for a 2x2 MIMO system, is selected. Note that $P L_{\max }$ depends on the input power $P_{T x}$ of the antenna and thus also on the output power of the power amplifier (which is $\eta \cdot P_{\text {el/amp }}$ ).

Once the maximum allowable path loss $P L_{\max }$ is known, the maximum range $R$ (in metres) covered by the base station of a certain technology can be determined:

$$
R=g^{-1}\left(\left(P L_{\max }-S M\right) \mid f, h_{B S}, h_{M S}\right)
$$

with $P L_{\max }$ the maximum allowable path loss (in $\mathrm{dB}$ ), $S M$ the shadowing margin (in $\mathrm{dB}$ ), $f$ the frequency (in $\mathrm{Hz}$ ), $h_{B S}$ the height of the base station (in metres) and $h_{M S}$ the height of the mobile station (in metres). The shadowing margin reflects the obstacles in the coverage area [39]. The shadowing margin is modelled by a lognormal distribution with a standard deviation, which depends on the environment. It also depends on the signal probability availability on the cell area i.e., the coverage requirement. Here, a coverage requirement of $90 \%$ is considered. The function $g($.$) depends on the used$ path loss model e.g., the HATA model and the Erceg model [41, 42]. The quantity before the "|" in eq. (7) is a variable and varies over a continuous interval, while the quantities after the "|" are parameters which only take one discrete known value.

\subsection{Parameter to quantify the power consumption and efficiency}

If multiple technologies are compared, it is very difficult to determine which one is the most energy-efficient: one technology could have a higher 
power consumption but also higher ranges, another one could have a smaller range but also a lower power consumption etc. Therefore, the power consumption $P C_{\text {area }}$ per covered area (in $\mathrm{W} / \mathrm{m}^{2}$ ) is defined to quantify the power consumption and efficiency for different technologies:

$$
P C_{\text {area }}=\frac{P_{e l}}{\pi \cdot R^{2}}
$$

with $P_{e l}$ the power consumption of the entire base station (in Watt) and $R$ the covered range (in $\mathrm{m}$ ). This parameter allows us to compare the energy efficiency of different wireless technologies and to determine which one is the most energy-efficient. The lower $P C_{\text {area }}$, the more energy-efficient the considered technology is.

\section{Tool for optimization of power consumption in wireless access networks}

The model described in Section 4 is used in the deployment tool GRAND (Green Radio Access Network Design) for design and optimization of green wireless access networks. The purpose of the tool is to cover a specific area, the target area, as energy-efficiently as possible with a wireless technology and with a minimal power consumption. Our tool GRAND can optimize the current network of an operator or can support the deployment of a new network. In the current version of the tool only existing base station sites are used. This means that the location of these sites and the heights of the antennas at these sites are fixed. The other settings (frequency, antenna gain and input power) are set to default settings which can be found in Table 2, but are changed when an existing network of an operator is optimized. In the current version there is no radiation pattern implemented i.e., it is assumed that the antenna transmits the same amount of power in each direction. Therefore, the coverage area of the base station is visualized by a circle. It is important to remark that only macrocell base stations are supported in the current version of the tool.

For the calculation of the optimal energy-efficient network, a genetic search algorithm is proposed. Fig. 2 gives a general overview of the used algorithm. Initially, all the base stations are inactive. A first set or population of solutions is generated by using the mutations (Block 1 in Fig. 2) which are also used in a future stage of the algorithm (Block 6 in Fig. 2). For this first population, each solution is created independently of the other solutions. For our tool, four different mutations are defined: 
- Make an inactive base station active.

- Make an active base station inactive.

- Add $1 \mathrm{dBm}$ to the input power of the antenna of an active base station.

- Remove $1 \mathrm{dBm}$ to the input power of the antenna of an active base station.

The first two mutations influence the locations of active base stations in the network and the last two the input power of the antenna of the base stations. The adaptation of a base station site occurs randomly. The size of this population i.e., the number of solutions that belong to a population, has to be selected by the user at the beginning of the algorithm. Each solution of the population is a possible network to cover the target area. This initial population will be improved through generations. A new generation population is created either by mutation of the current population or by selection of the best solutions in the population and adding new solutions by the crossover operator until the chosen population size is reached. The new population is then used in the next iteration of the algorithm until a stopping criterion is met. Fig. 2 gives a general overview of the used algorithm.

[Fig. 2 about here.]

A new generation can be formed by selecting a number of solutions of the current generation population (Block 4 in Fig. 2). This selection is based on the fitness of the solution (Block 3 in Fig. 2). This fitness is a function that measures the quality of the solution and is always problem dependent. For this problem, two different fitness functions are combined to one global fitness function. In this way, both the coverage of the target area and the associated power consumption are taken into account. The first fitness function is the coverage fitness $f_{\text {cov }}$ and is defined as:

$$
f_{\text {cov }}=100 \cdot \frac{A_{\text {target }} \cap A_{\text {sol }}}{A_{\text {target }}}
$$

with $A_{\text {target }}$ the area of the target area to be covered (in $\left.\mathrm{km}^{2}\right), A_{\text {sol }}$ the area covered by the individual solution (in $\mathrm{km}^{2}$ ) and $\cap$ represents the cross-section of the two areas. $f_{\text {cov }}$ is expressed as a percentage and indicates how good the target area is covered by the individual solution. The higher $f_{\text {cov }}$, the better 
the area covered by the individual solution corresponds with the target area.

The second fitness function is the power consumption fitness $f_{\text {pow }}$ and is defined as:

$$
f_{\text {pow }}=100-\left(\frac{P_{\text {sol }}}{P_{\max }} \cdot 100\right)
$$

with $P_{\text {sol }}$ the power consumption of the individual solution (in Watt) and $P_{\text {max }}$ the power consumption of the most energy-inefficient network (in Watt) i.e., the network with the highest power consumption, to cover the target area. To determine $P_{\max }$, the highest possible power consumption of each base station site in the target area is determined using eq. (3) when the input power of the antennas is maximal (see Table 2). $P_{\max }$ is then used as a reference to decide whether a solution is better than the other or not. The most energy-inefficient network is chosen because during the run it is not known what the most energy-efficient network is.

Eq. (9) and (10) are then combined in one global fitness function $f_{\text {tot }}$ defined as:

$$
f_{\text {tot }}=f_{\text {cov }}+k\left(f_{\text {cov }}\right) \cdot f_{\text {pow }}
$$

with

$$
k\left(f_{\text {cov }}\right)=\left\{\begin{array}{lr}
0, & f_{\text {cov }}<90 \\
5 \cdot\left(\frac{f_{c o v}-90}{5}\right)^{2}, & 90 \leq f_{\text {cov }}<95 \\
5, & \text { else }
\end{array}\right.
$$

$f_{\text {tot }}$ will have a value between 0 and 600 . The maximum value (600) is obtained when both $f_{\text {cov }}$ and $f_{\text {pow }}$ equal 100. The higher $f_{\text {tot }}$, the better the solution is. This kind of global fitness function is chosen because of the trade-off between coverage and power consumption. A coverage requirement of $90 \%$ is often used by wireless operators for wireless network design. If the coverage is below the $90 \%$ it is important to optimize the coverage. Therefore, a factor $k\left(f_{\text {cov }}\right)$ of 0 is chosen when the coverage is below $90 \%$. In that way, the coverage requirement can be (easily) obtained. A coverage requirement of $95 \%$ is assumed as an excellent coverage and is therefore be chosen as an upper bound. When the coverage approaches $95 \%$, the coverage requirement is certainly met and the most important task is to minimize the power consumption while preserving a coverage of at least $90 \%$. The closer the coverage is to $95 \%$, the more important it becomes to start optimizing the power consumption in the network. Therefore, the factor $\mathrm{k}$ (fcov) is higher for larger values of the coverage requirement. A quadratic function is used 
to assign a higher importance to higher coverage percentages. Important to remark, is that the boundaries of 90 and 95 in eq. (11) can be chosen freely. About $90 \%$ of the solutions will be selected for the new population. The other $10 \%$ will be removed from the population. Those are the solutions with the lowest value for $f_{\text {tot }}$.

In the next step, a new population of the appropriate size, given by the user at the beginning of the algorithm, will be generated, based on the selected solutions. To fill up the population, new solutions are generated with the crossover operator (Block 5 in Fig. 2). For this, two parent solutions are chosen: one of the removed solutions of the previous generation population is chosen as base, for the other parent solution one of the selected (good) solutions is used. Each solution has a number of partial solutions which cover a small area of the target area. The part of the target area covered by each partial solution should be the same for all the solutions generated by our algorithm. The partial solutions of the bad parent solution are compared with the corresponding partial solutions of the good parent solution. The bad solution is chosen as base because in this way, the possibility that the algorithm stops in a local optimum is reduced. If a partial solution of the good parent solution is better than that of the bad parent solution, the partial solution is adapted in the bad parent solution. This new obtained solution is then added to the new generation population.

Only every 50 generations a new generation is made based on the crossover operator. Therefore, it is checked whether the number of each generation is divisible by 50 (Block 8 in Fig. 2). If this is the case, a new generation is generated by the selection and crossover operator, otherwise a new generation is created with the mutation operator. The crossover operator is only used every 50 th generation because this operation is very time-consuming.

Each solution of a population will also be mutated (Block 6 in Fig. 2). The solution will be adapted only when a better global fitness is obtained. The above mentioned mutations will be used.

The previous steps are repeated until a stopping criterion is met (Block 7 in Fig. 2). The algorithm is stopped when the distribution function of the fitness of the population is not changed significantly from the distribution function of the previous population. When the estimated value of the $f_{\text {tot }}$ distribution function of the new population is lower than a threshold of $1 \%$ of the previous population, the algorithm is stopped. The maximum running time and the maximum number of generations can also be used as stopping criteria. The final result is then the solution with the highest fitness. 


\section{Results: comparison for one base station}

\subsection{Configuration}

In this investigation, the base stations are placed outdoor in a suburban environment. Only macro cells with a transmitting antenna height of $30 \mathrm{~m}$ are considered here. As model for the mobile stations, a laptop with a Wireless Network Interface Card (WNIC) is considered for all technologies except for fixed WiMAX. For fixed WiMAX a residential gateway is considered. The mobile stations are used indoor. Table 3 summarizes the configuration parameters for all technologies described in Section 3.

[Table 3 about here.]

We define two configurations for the outdoor base stations: a basic reference configuration and a future extended configuration. In the basic reference configuration, one receiving $(\mathrm{Rx})$ and one transmitting $(\mathrm{Tx})$ antenna is considered, i.e., a SISO (Single Input Single Output) system. In the extended configuration, both the base station and the receiver have multiple antennas, i.e., a MIMO (Multiple Input Multiple Output) system. Here, a 2x2 MIMO system ( $2 \mathrm{Tx}$ and $2 \mathrm{Rx}$ antennas) is considered. The reference configuration is supported by all the considered technologies, the extended configuration only by mobile WiMAX, HSPA and LTE.

The frequencies used for the link budget calculations of the different technologies are the following: $2.5 \mathrm{GHz}$ for mobile WiMAX, 3.5 GHz for fixed WiMAX, 2.1 GHz for UMTS and HSPA, and 2.6 GHz for LTE. In this paper, the Erceg model is used [42]. This model was developed in 1999 by Erceg et al. and is based on experimental data in different suburban areas. It has categorized three different terrain categories: category $\mathrm{A}$ is the maximum path loss category and corresponds with moderate-to-heavy tree densities, category B can be characterized as either mostly flat terrain with moderateto-heavy tree densities or hilly terrain with light tree densities and category $\mathrm{C}$ is the minimum path loss category which is mostly flat terrain with light three densities. The model defines different values for its parameters according to the used category. For this investigation, Erceg $\mathrm{C}$ is chosen because this is the best suitable for the suburban areas in Belgium [43]. 


\subsection{Comparison of the considered technologies}

In this section, the considered wireless technologies are compared for a bandwidth of approximately $5 \mathrm{MHz}$. Fixed WiMAX is the only technology that does not support a bandwidth of $5 \mathrm{MHz}$. The bandwidth supported by fixed WiMAX closest to $5 \mathrm{MHz}$ is $3.5 \mathrm{MHz}$. The parameters of Tables 1,2 and 3 are used for this analysis.

Fig. 3 shows the power consumption $P C_{\text {area }}$ (in $\mathrm{mW} / \mathrm{m}^{2}$ ) as a function of the bit rate (in Mbps) for the considered technologies. In general, one can see that for each technology $P C_{\text {area }}$ increases for increasing bit rates and thus becomes less energy-efficient for higher bit rates. For mobile WiMAX, fixed WiMAX, HSPA and LTE, this can be explained by the fact that higher bit rates correspond with higher receiver SNRs as shown in Table 2. Higher receiver SNRs correspond with smaller ranges: from eq. (8) one can see that a higher $P C_{\text {area }}$ corresponds then with a smaller range for the same $P_{e l}$. For UMTS, the processing gain is mainly responsible for the decrease in energy efficiency when higher bit rates are used. Table 2 lists the processing gain for the three considered UMTS services. The higher the bit rate of the service, the lower the processing gain. A lower processing gain results in a lower range for the same power consumption and thus UMTS becomes also less energy-efficient for higher bit rates.

[Fig. 3 about here.]

Based on the assumptions made for the parameters, UMTS is the most energy-efficient technology until a bit rate of $2.8 \mathrm{Mbps}$, LTE between $2.8 \mathrm{Mbps}$ and 8.2 Mbps, fixed WiMAX between 8.2 Mbps and 13.8 Mbps and finally mobile WiMAX for bit rates higher than $13.8 \mathrm{Mbps}$.

E.g., for a bit rate of $2 \mathrm{Mbps}, P C_{\text {area }}$ is $0.5 \mathrm{~mW} / \mathrm{m}^{2}$ for UMTS while $P C_{\text {area }}=0.7 \mathrm{~mW} / \mathrm{m}^{2}$ for fixed WiMAX and $P C_{\text {area }}=1.9 \mathrm{~mW} / \mathrm{m}^{2}$ for HSPA. Mobile WiMAX and LTE do not support bit rates below the $2.8 \mathrm{Mbps}$ for the considered bandwidth. UMTS performs better than fixed WiMAX because of its higher ranges (1015.4 $\mathrm{m}$ versus $788.8 \mathrm{~m}$ at $2 \mathrm{Mbps}$ ), despite the fact that it has a higher power consumption $P_{e l}(1672.6 \mathrm{~W})$ than fixed WiMAX $(1279.1 \mathrm{~W})$. This higher range is due to the UMTS processing gain (Section 4). The higher power consumption of UMTS is caused by the higher input power $P_{T x}$ of the antenna (43 dBm versus $35 \mathrm{dBm}$ for fixed WiMAX, Section 4): a higher $P_{T x}$ corresponds with a higher $P_{\text {el/amp }}$ for the power amplifier in eq. (2), resulting in a higher $P_{e l}$ of the entire base station. 
HSPA is the least energy-efficient technology at 2 Mbps because of its lower ranges. Table 2 shows that the effective input power of the antenna $P_{T x}^{T C H}$ is lower for HSPA (24.7 dBm, Section 4). The $P_{e l}$ of HSPA is the same as for UMTS.

From 2.8 Mbps to $8.2 \mathrm{Mbps}$, LTE is the most energy-efficient technology. LTE has an input power of the antenna of $43 \mathrm{dBm}$ resulting in higher ranges (557.0 $\mathrm{m}$ at $5 \mathrm{Mbps}$ ) and a $P_{e l}$ of $1672.6 \mathrm{~W}$. UMTS does not support bit rates higher than 3 Mbps.

From 8.2 Mbps to $13.8 \mathrm{Mbps}$, fixed WiMAX is the most energy-efficient solution. Fixed WiMAX performs better than LTE because of its lower receiver SNR, its higher antenna gain for the mobile station ( $8 \mathrm{dBi}$ versus $0 \mathrm{dBi}$ ) and its lower noise figure ( $4.6 \mathrm{~dB}$ versus $8 \mathrm{~dB}$ ) resulting in higher ranges (e.g., $407.7 \mathrm{~m}$ versus $346.3 \mathrm{~m}$ at $10 \mathrm{Mbps}$ ). Furthermore, fixed WiMAX has a lower $P_{e l}$ (e.g., $1279.1 \mathrm{~W}$ versus $1672.6 \mathrm{~W}$ at $10 \mathrm{Mbps}$ ) due to its lower input power of the antenna ( $35 \mathrm{dBm}$ versus $43 \mathrm{dBm})$. Fixed WiMAX and mobile WiMAX have the same $P_{e l}(1279.1 \mathrm{~W})$. Fixed WiMAX has higher ranges than mobile WiMAX for the same reasons as for LTE, except for the receiver SNRs.

For bit rates higher than $13.8 \mathrm{Mbps}$, mobile WiMAX is the most energyefficient solution based on our assumptions. Only mobile WiMAX and LTE support these higher bit rates. Mobile WiMAX performs better because of its higher range (e.g., $215.7 \mathrm{~m}$ versus $193.5 \mathrm{~m}$ at $17 \mathrm{Mbps}$ ) and its lower $P_{e l}$ (e.g., $1279.1 \mathrm{~W}$ versus $1672.6 \mathrm{~W}$ at $17 \mathrm{Mbps}$ ). This is due to its lower receiver SNRs. The lower $P_{e l}$ is caused by the lower input power of the antenna (35 dBm versus $43 \mathrm{dBm})$.

\subsection{Influence of $M I M O$}

The influence of MIMO on the energy efficiency of the considered technologies is investigated in this section. Only mobile WiMAX, HSPA, and LTE support the extended configuration. A 2x2 MIMO system is considered for a bandwidth of $5 \mathrm{MHz}$. The parameters of Tables 1, 2 and 3 are used.

Fig. 4 shows the power consumption $P C_{\text {area }}$ per covered area (in $\mathrm{mW} / \mathrm{m}^{2}$ ) as a function of the bit rate (in Mbps). Based on the assumptions made for the parameters, HSPA is the most energy-efficient technology until a bit rate of $2.8 \mathrm{Mbps}$, LTE between $2.8 \mathrm{Mbps}$ and $9 \mathrm{Mbps}$, and mobile WiMAX for bit rates higher than 9 Mbps.

[Fig. 4 about here.] 
LTE performs better than mobile WiMAX up to 9 Mbps because of its lower receiver SNRs corresponding with the considered bit rates (Table 2). Furthermore, LTE performs better than HSPA due to its higher input power of the antenna ( $43 \mathrm{dBm}$ versus $24.7 \mathrm{dBm}$, Section 4 ).

For bit rates higher than $9 \mathrm{Mbps}$, mobile WiMAX is the most energy-efficient technology. This is due to its lower receiver SNRs compared to LTE and its higher input power of the antenna compared to HSPA (35 dBm versus $24.7 \mathrm{dBm}$, Section 4).

Table 4 compares the range, $P_{e l}$ and $P C_{\text {area }}$ for mobile WiMAX, HSPA and LTE for both the reference and the extended configuration. A bit rate of $11 \mathrm{Mbps}$ is assumed for both the configurations. Furthermore, a bandwidth

of $5 \mathrm{MHz}$ is considered. For mobile WiMAX the 3/4 16-QAM modulation is chosen, for HSPA the 3/4 64-QAM and for LTE the 1/2 16-QAM.

[Table 4 about here.]

Table 4 shows that with the $2 \times 2$ MIMO system ranges are obtained which are about $44 \%$ higher compared to the SISO system due to the MIMO gain (Table 2). $\quad P_{e l}$ is for a 2x2 MIMO system about $32 \%$ higher for mobile WiMAX and about $60 \%$ for HSPA and LTE caused by the extra equipment (multiple power amplifiers and transceivers) needed to support MIMO (Section 4). However, this still results in a higher energy efficiency: $P C_{\text {area }}$ decreases by about $36 \%$ for mobile WiMAX and $23 \%$ for HSPA and LTE compared to the SISO system. It is clear that the introducing of MIMO results in a higher energy efficiency for all considered technologies.

\section{Application: prediction of power consumption of a wireless ac- cess network in Brussels}

In this section, the decrease in required electrical power needed to cover a pre-defined area (namely Brussels Capital Region, Belgium) with base stations of each technology is investigated. For this investigation, a new network is deployed for each technology. However, only existing base station sites are used. The location of the existing base station sites, along with other characteristics of the base station sites, are retrieved from a shapefile supplied by BIPT (Belgisch Instituut voor Postdiensten en Telecommunication) [44]. A shapefile stores non-topological geometry and attribute information for the 
spatial features in the data set [45]. The geometry of a feature is stored as a shape comprising a set of vector coordinates. A total number of 8095 antennas spread over 840 base station sites and exploited by four different operators can be found in the shapefile. Three different sorts of base stations occur in the shapefile: GPRS (General Packet Radio Service) sites (5262 antennas at 764 sites), UMTS sites (2446 antennas at 538 sites) and (fixed) WiMAX sites (387 antennas at 86 sites). Some sites support more than one technology.

Fig. 5(a) shows the target area that needs to be covered. This target area is Brussels Capital Region $\left(149 \mathrm{~km}^{2}\right)$ in Belgium. This region consists of 19 different communities such as Brussels City $\left(33 \mathrm{~km}^{2}\right)$, Schaerbeek, Anderlecht, Uccle, etc [48]. Furthermore, Brussels city is much smaller, has a lower population density, lower buildings and a lower number of high buildings than cities like New York, Tokyo, Los Angeles and Shanghai which are typical examples of urban areas. Therefore, it is assumed that Brussels Capital Region is a suburban area [49]. Fig. 5(b) gives an overview of the existing base station sites in Brussels retrieved from the shapefile of BIPT [44]. Brussels will be covered with each technology. To make a fair comparison, a bit rate of $1 \mathrm{Mbps}$ is assumed for the reference configuration and the extended configuration. For mobile WiMAX, the 3/4 QPSK modulation is chosen for a bandwidth of $1.25 \mathrm{MHz}$ which means that 85 subcarriers out of 128 subcarriers are used [15]. For fixed WiMAX, the 1/2 BPSK modulation is chosen [16], for UMTS the AMR 12.2 Voice service [17], for HSPA the 1/4 QPSK modulation [18] and for LTE the 1/2 QPSK for a bandwidth of $1.4 \mathrm{MHz}$ which corresponds with 76 used subcarriers out of 128 subcarriers [19]. The algorithm stops running when the estimated value of the $f_{\text {tot }}$ distribution function of a new generation population is not $1 \%$ higher than the estimated value of the $f_{\text {tot }}$ distribution function of the old population. Furthermore, the algorithm will also stop when 5000 generations are generated or when the simulation lasts longer than 14400 s (i.e, 4 hours). During the simulations, the algorithm was always stopped by the distribution criterion for all the considered technologies. Each population contains 100 possible solutions. The solution with the highest global fitness $f_{\text {tot }}$ of the last generation is the final network.

[Fig. 5 about here.]

The selection of the active base station antennas and the input power of 
the antenna of the selected base stations are optimized for a higher energy efficiency (lowest $P C_{\text {area }}$ ). Fig. 5(c), 5(d), 5(e), 5(f), 5(g) and 5(h) illustrate the most energy-efficient deployment (resulting from the tool) in Brussels for respectively, mobile WiMAX SISO, HSPA SISO, LTE SISO, mobile WiMAX 2x2 MIMO, LTE 2x2 MIMO and HSPA 2x2 MIMO. Table 5 lists the numerical results for all the considered technologies. For the reference configuration, the best solution to cover Brussels is LTE, in contrary to the $5 \mathrm{MHz}$ channel where UMTS performs the best (Section 6.2). For 1 Mbps and a SISO channel, high ranges are obtained with LTE resulting in a high energy efficiency $\left(P C_{\text {area }}=0.7 \mathrm{~mW} / \mathrm{m}^{2}\right)$, a low number of used base station sites (135) and thus a low total power consumption $(101.3 \mathrm{~kW})$. The high ranges obtained with LTE are due to the low receiver SNR for the considered modulation and coding rate. HSPA is the second most energy-efficient technology $\left(P C_{\text {area }}\right.$ $\left.=1.6 \mathrm{~mW} / \mathrm{m}^{2}\right)$ followed by UMTS $\left(P C_{\text {area }}=2.3 \mathrm{~mW} / \mathrm{m}^{2}\right)$ and WiMAX $\left(P C_{\text {area }}=2.7 \mathrm{~mW} / \mathrm{m}^{2}\right.$ for fixed WiMAX and $P C_{\text {area }}=3.2 \mathrm{~mW} / \mathrm{m}^{2}$ for mobile WiMAX). With UMTS higher ranges can be obtained than with fixed WiMAX as discussed in Section 6.2. These higher ranges result in a lower number of used base station sites (200) and thus in a lower total power consumption (330.1 kW) than for fixed WiMAX (306 sites and $389.1 \mathrm{~kW}$ respectively). Furthermore, fixed WiMAX performs slightly better than mobile WiMAX. The fixed and mobile WiMAX base stations have the same power consumption but higher ranges can be obtained with fixed WiMAX than with mobile WiMAX (Section 6.2), resulting again in a higher energy efficiency.

[Table 5 about here.]

LTE is also the best solution for the extended configuration based on the assumptions made for the parameters, the considered MIMO system and a bit rate of 1 Mbps. LTE has the lowest power consumption, the highest total fitness and needs the lowest number of base stations (Table 5). Table 5 shows that the considered technologies have a higher energy efficiency for the extended configuration than for the reference configuration. In general, a 2x2 MIMO system increases the coverage compared to a SISO system. Because of this, less base station sites are needed to cover Brussels, resulting in a lower total power consumption and thus in a higher energy efficiency.

For comparison, the total power consumption for a current UMTS network in Brussels with a coverage of $97.6 \%$ is $732.7 \mathrm{~kW}$. With our tool a total 
power consumption of $330.1 \mathrm{~kW}$ is obtained for a coverage of $96.5 \%$. The total power consumption of a current fixed WiMAX network in Brussel is $566.9 \mathrm{~kW}$ for a coverage of $38.7 \%$. With our tool a total power consumption of $389.1 \mathrm{~kW}$ for a coverage of $95.0 \%$ is obtained. For the other technologies, no current networks are available. These results shows that the current networks can be optimized regarding the energy consumption.

\section{Conclusions and future research}

In this paper, the power consumption for five different wireless technologies, namely mobile WiMAX, fixed WiMAX, UMTS, HSPA and LTE is investigated based on the parameter assumptions for the five technologies. This power consumption is then related to the coverage of the base station. The base stations (macro cells) are placed outdoor and for the mobile stations a laptop with a Wireless Network Interface Card (WNIC) for mobile WiMAX, UMTS, HSPA and LTE and a residential gateway for fixed WiMAX is considered. The energy efficiency per covered area $P C_{\text {area }}$ was defined and compared for different bit rates and for the considered technologies (bandwidth of approximately $5 \mathrm{MHz}$ ). Lower $P C_{\text {area }}$ values mean that the technology is more energy-efficient.

Based on the assumptions made for the parameters and a $5 \mathrm{MHz}$ channel, UMTS is the most energy-efficient technology until a bit rate of $2.8 \mathrm{Mbps}$, LTE between 2.8 Mbps and 8.2 Mbps, fixed WiMAX between the 8.2 Mbps and $13.8 \mathrm{Mbps}$ and finally mobile WiMAX for bit rates higher than $13.8 \mathrm{Mbps}$.

Furthermore, the influence of MIMO is investigated for mobile WiMAX, HSPA and LTE. A bandwidth of $5 \mathrm{MHz}$ and a 2x2 MIMO system are assumed. HSPA is the most energy-efficient technology until a bit rate of 2.8 Mbps, LTE between 2.8 Mbps and $9 \mathrm{Mbps}$, and mobile WiMAX for bit rates higher than $9 \mathrm{Mbps}$.

The 2x2 MIMO system is also compared to the SISO system. For the range an increase of $44 \%$ is found for the three technologies. The power consumption increases by $32 \%$ for mobile WiMAX and $60 \%$ for HSPA and LTE, resulting in a decrease of the $P C_{\text {area }}$ by $36 \%$ for mobile WiMAX and $23 \%$ for HSPA and LTE.

The theoretical power consumption and coverage model for the base stations is used in the prediction tool GRAND (Green Radio Access Network Design) and applied on the Brussels capital region. A genetic based algorithm was proposed for designing green wireless access networks. Appropriated mu- 
tation, selection and crossover operators are defined. Furthermore, a fitness function is designed specifically for this problem. The proposed tool can be used for network planning with optimal energy efficiency. Results from this tool show that LTE is the best solution for both the SISO (1 Mbps) and 2x2 MIMO (1 Mbps) system to cover the Brussels capital region under the assumptions made for the parameters and the considered bit rate.

Future research will consist of including micro cells to cover smaller areas in the model of Section 4. Also the influence of the number of active users on the range (cell breathing) and thus the power efficiency will be investigated. When there is little or no activity in the area of the base station, the base station could be switched off (cell breathing). Nowadays, this is not supported by the base station but this should be part of future research. The sleep modes have to be combined with an advanced management algorithm and will have a positive influence on the power consumption and energy efficiency $[7,8,9,10,13]$. In the GRAND tool, the next step is to add the support for directional antennas and new network deployments.

\section{Acknowdledgment}

W. Joseph is a Post-Doctoral Fellow of the FWO-V (Research Foundation Flanders).

\section{References}

[1] M. Pickavet, W. Vereecken, S. Demeyer, P. Audenaert, B. Vermeulen, C. Develder, D. Colle, B. Dhoedt, P. Demeester, Worldwide Energy Needs for ICT: the Rise of Power-Aware Networking, 2008 IEEE ANTS Conference, Bombay, India, December 2008, pp. 1-3.

[2] Cisco White Paper, Cisco Visual Network Index: Forecast and Methodology 2008-2013, 2008.

[3] World Wireless Research Forum, www.wireless-world-research.org, 2009.

[4] Ericsson White Paper, Sustainable energy use in mobile communications, 2007.

[5] M. Etoh, T. Ohya, Y. Nakayama, Energy Consumption Issues on Mobile Network Systems, International Symposium Issues on Mobile Network Systems, 2008, pp. 365-368. 
[6] W. Vereecken, W. Van Heddeghem, M. Deruyck, B. Puype, B. Lannoo, W. Joseph, D. Colle, L. Martens, M. Pickavet, Power Consumption in Telecommunication Networks: Overview and Reduction Strategies, Green Communications Magazine, Accepted for publication 08/2010.

[7] L. Saker, S. E. Elayoubi, Sleep mode implementation issues in green base stations, the 21st Annual IEEE International Symposium on Personal, Indoor and Mobile Radio Communications (PIMRC 2010), Istanbul, Turkey, September 2010, pp. 1681-1686.

[8] R. Litjens and L. Jorguseski, Potential of Energy-Oriented Network Optimisation: Switching Off Over-Capacity in Off-Peak Hours, the 21st Annual IEEE International Symposium on Personal, Indoor and Mobile Radio Communications (PIMRC 2010), Istanbul, Turkey, September 2010, pp. 1658-1662.

[9] M. A. Marsan, L. Chiaraviglio, D. Ciullo, M. Meo, Optimal Energy Savings in Cellular Access Networks, IEEE International Conference on Communications Workshops 2009, Dresden, Germany, June 2009, pp. $1-5$.

[10] Y. Qi, M. Imran and R. Tafazolli, On the Energy Aware Deployment Strategy in Cellular Systems, the 21st Annual IEEE International Symposium on Personal, Indoor and Mobile Radio Communications: Workshop on Wireless Green (PIMRC 2010, W-GREEN), Istanbul, Turkey, September 2010, pp. 362-366.

[11] M. Jada, J. Hämäläinen, R. Jäntti, M. M. A. Hossain, Power Efficiency Model for Mobile Access Network, the 21st Annual IEEE International Symposium on Personal, Indoor and Mobile Radio Communications: Workshop on Wireless Green (PIMRC 2010, W-GREEN), Istanbul, Turkey, September 2010, pp. 316-321.

[12] F. Richter, A.J. Fehske, G.P. Fettweis, Energy Efficiency Aspects of Base Station Deployment Strategies for Cellular Networks, IEEE 70th Vehicular Technology Conference Fall (VTC 2009-Fall), Anchorage, Alaska, September 2009, pp. 1-5.

[13] G. Micallef, P. Mogensen, H.-O. Scheck, Cell Size Breathing and Possibilities to Introduce Cell Sleep Mode, European Wireless Conference 2010, Lucca, Italy, April 2010, pp. 111-115. 
[14] G. Koutitas, Low Carbon Network Planning, European Wireless conference 2010, Lucca, Italy, April 2010, pp. 411-417.

[15] Part 16: Air Interface for Fixed and Mobile Broadband Wireless Access Systems: Amendment 2: Physical and Medium Access Control Layers for Combined Fixed and Mobile Operation in Licensed bands and Corrigendum 1, IEEE Computer Society and the IEEE Microwave Theory and Techniques Society, February 2006.

[16] Air Interface for Fixed Broadband Wireless Access Systems, IEEE Computer Society and the IEEE Microwave Theory and Techniques Society, October 2004.

[17] 3rd Generation Partnership Project; Technical Specification Group Radio Access Network; UE Radio Transmission and Reception (TDD) (Release 1999), TR 25.102 v3.13.0, 3GPP, October 2006.

[18] 3rd Generation Partnership Project: Technical Specification Group Radio Access Network: Physical layer aspects of UTRA High Speed Downlink Packet Access (Release 4), TR 25.848 v4.0.0., 3GPP, March 2001.

[19] LTE: 3rd Generation Partnership Project: Technical Specification Group Radio Access Network: Evolved Universal Terrestrial Radio Access (EUTRA): User Equipment (UE) radio transmission and reception (TS 36.101 v9.1.0 Release 9), 3GPP, September 2009.

[20] TeliaSonera, TeliaSonera first in the world with $4 G$ services, $\quad$ www.teliasonera.com/News-and-Archive/Pressreleases/2009/TeliaSonera-first-in-the-world-with-4G-services/, December 2009.

[21] M. Deruyck, E. Tanghe, W. Joseph, W. Vereecken, M. Pickavet, L. Martens, B. Dhoedt, Model for Power Consumption of Wireless Access Networks, IET Science, Measurement \& Technology, accepted for publication $03 / 2011$.

[22] U. Barth, Wireless Networks, EARTH research project, ETSI Green Agenda Workshop, Cannes, France, November 2009.

[23] P. Gildert, Power System Efficiency in Wireless Communication, Ericsson, January 2006. 
[24] L. Hérault, Green Wireless Communications eMobility GA1, e-Mobility Workshop at the 4th Future Networks Concertation Meetings, Brussels, Belgium, September 2009.

[25] M. Deruyck, W. Vereecken, E. Tanghe, W. Joseph, M. Pickavet, L. Martens, P. Demeester, Power consumption in wireless access networks, European Wireless Conference 2010, Lucca, Italy, April 2010, pp. 924931.

[26] M. Deruyck, W. Vereecken, E. Tanghe, W. Joseph, M. Pickavet, L. Martens, P. Demeester, Comparison of power consumption of mobile WiMAX, HSPA and LTE access networks, 9th Conference of Telecommunication, Media and Internet Techno-Economics (CTTE), Ghent, Belgium, June 2010, pp. 1-6.

[27] Pfannenberg, http://www.pfannenbergusa.com/catalog/catalogdownloads/2010_Catalog.pdf, 2010.

[28] F.H. Raab, P. Asbeck, S. Cripps, P.B. Kenington, Z.B. Popovic, N. Pothecary, J.F. Sevic, N.O. Sokal, RF and Microwave Power Amplifiers and Transmitter Technologies - Part 1, High Frequency Electronics, May 2003, pp. 22-36.

[29] R. Bhagavatula, R.W. Heath Jr., K. Linehan, Performance Evaluation of MIMO Base Station Antenna Designs, Antenna Systems \& Technology, vo. 11, no. 6, 2010, pp. 14-17.

[30] Ophir RF, model 5303009, 5303025, 5303075, 2010.

[31] Power-One S series, 2010.

[32] Daikin FUQ125BW13/R2Q125D7413, 2010.

[33] Allgon Microwave - AMR Transcend PLUS, 2010.

[34] Ceragon Networks - FibeAIR 1500P Family, 2010.

[35] Trangobroadbandnetworks - TrangoLINK - Giga, 2010.

[36] S. Saunders, Antennas and Propagation for Wireless Communication Systems, Wiley, 1999. 
[37] R. Krüger, H. Mellein, UMTS Introduction and Measurement, Rohde \& Schwarz, 2004.

[38] J. Hämäläinen, Cellular Network Planning and Optimization - Part VII: WCDMA link budget, Helsinki University of Technology, 2008.

[39] L. Nuaymi, WiMAX Technology for Broadband Wireless Access, Wiley, 2007.

[40] M. Deruyck, E. Tanghe, W. Joseph, D. Pareit, I. Moerman, L. Martens, Performance Analysis of WiMAX for mobile Applications, IEEE Wireless Communications and Networking Conference, Sydney, Australia, April 2010, pp. 1-7.

[41] M. Hata, Empirical Formula for Propagation Loss in Land Mobile Radio Services, IEEE Transactions on Vehicular Technology, vo. 29, no. 3, 1980, pp. 317-325.

[42] V. Erceg, L. Greenstein, S. Tjandra, S. Parkoff, A. Gupta, B. Kulic, A. Julius, R. Bianchi, An Empirically Based Path Loss Model for Wireless Channels in Suburban Environments, IEEE Journal on Selected Areas in Communications, vo. 7 , no. 7, 1999, pp. 1205-1211.

[43] J. De Bruyne, W. Joseph, D. Plets, L. Verloock, E. Tanghe, L. Martens, Comparison of the link budget with experimental performance of a WiMAX system, EURASIP Journal on Wireless Communications and Networking, vol. 2009, Article ID 247436, 2009.

[44] Belgisch Instituut voor Postdiensten en Telecommunicatie (BIPT), www.sites.bipt.be, 2008.

[45] ESRI, ESRI Shapefile Technical Description - White Paper, 1998.

[46] D. Plets, W. Joseph, L. Verloock, L. Martens, H. Gauderis, E. Deventer, Extensive Penetration Loss Measurements and Models for Different Building Types for DVB-H in the UHF Band, IEEE Transactions on broadcasting, vo. 55, no. 2, 2009, pp. 213-222.

[47] S. A. Basit, Dimensioning of the LTE network: Description of Models and Tools, Coverage and Capacity Estimation of 3GPP Long Term Evolution radio interface, Helsinki University of Technology, 2009. 
[48] http://www.bruxelles.irisnet.be/en/region/region_de_bruxellescapitale/communes/bruxelles_ville.shtml, November 2010.

[49] J. De Bruyne, W. Joseph, L. Martens, C. Olivier, W. De Ketelaere, Field measurement and performance analysis of an 802.16 system in a suburban environment, IEEE Trans. Wireless Commun, vol. 8, no. 3, pp. 1424 1434, March 2009. 


\begin{tabular}{|l|c|c|}
\hline Equipment & Parameter & Power consumpotion \\
\hline Digital signal processing & $P_{\text {el/proc }}$ & $100 \mathrm{~W}$ \\
\hline \multirow{2}{*}{ Power amplifier (SISO) } & $\eta$ & $12.8 \%$ \\
\cline { 2 - 3 } & $P_{e l / a m p}$ (max.) & $156 \mathrm{~W}$ \\
\hline \multirow{2}{*}{ Power amplifier (MIMO) } & $\eta$ & $11.5 \%$ \\
\cline { 2 - 3 } & $P_{e l / a m p}$ (max.) & $10.4 \mathrm{~W}$ \\
\hline Transceiver & $P_{\text {el/trans }}$ & $100 \mathrm{~W}$ \\
\hline Rectifier & $P_{e l / r e c t}$ & $100 \mathrm{~W}$ \\
\hline Air conditioning & $P_{\text {el/airco }}$ & $225 \mathrm{~W}$ \\
\hline Microwave link & $P_{\text {el/micro }}$ & $80 \mathrm{~W}$ \\
\hline
\end{tabular}

Table 1: Power consumption of the base station components for the considered technologies (mobile WiMAX, fixed WiMAX, UMTS, HSPA and LTE). 


\begin{tabular}{|c|c|c|c|c|c|c|}
\hline Parameter & Mobile WiMAX & Fixed WiMAX & UMTS & HSPA & LTE & Unit \\
\hline Input power of base station $P_{T x}$ & 35 & 35 & 43 & 43 & 43 & $\mathrm{dBm}$ \\
\hline Effective input power of base station $P_{T x}^{T C H}$ & 35 & 35 & {$\left[\begin{array}{llll}25.4 & 37.5 & 31.5\end{array}\right]^{3}$} & 24.7 & 43 & $\mathrm{dBm}$ \\
\hline Antenna gain of base station & 16 & 17 & 17.4 & 17.4 & 18 & $\mathrm{dBi}$ \\
\hline Antenna gain of mobile station & 2 & 8 & 0 & 0 & 0 & $\mathrm{dBi}$ \\
\hline Number of MIMO Tx antennas & 1,2 & 1 & 1 & 1,2 & 1,2 & $=$ \\
\hline Number of MIMO Rx antennas & 1,2 & 1 & 1 & 1,2 & 1,2 & - \\
\hline MIMO gain & $\begin{array}{c}1 \times 1: 0 \\
2 \times 2: 3.5\end{array}$ & $\begin{array}{c}\text { 1x1: } 0 \\
0\end{array}$ & $\begin{array}{c}\text { 1x1: } 0 \\
0\end{array}$ & $\begin{array}{c}1 \times 1: 0 \\
2 \times 2: 3.5\end{array}$ & $\begin{array}{c}1 \times 1: 0 \\
2 \times 2: 3.5\end{array}$ & $\mathrm{~dB}$ \\
\hline Cyclic combining gain of base station & 3 & 3 & 3 & 3 & 3 & $\mathrm{~dB}$ \\
\hline Soft handover gain & 0 & 0 & 1.5 & 1.5 & 0 & $\mathrm{~dB}$ \\
\hline Feeder loss of base station & 0.5 & 0.5 & 2 & 0 & 2 & $\mathrm{~dB}$ \\
\hline Feeder loss of mobile station & 0 & 0 & 0 & 0 & 0 & $\mathrm{~dB}$ \\
\hline Fade margin & 10 & 10 & 10 & 10 & 10 & $\mathrm{~dB}$ \\
\hline Yearly availability & 99.995 & 99.995 & 99.995 & 99.995 & 99.995 & $\%$ \\
\hline Cell interference margin & 2 & 0 & 0 & 2 & 2 & $\mathrm{~dB}$ \\
\hline User interference margin & 0 & 0 & 6 & 9 & 0 & $\mathrm{~dB}$ \\
\hline Bandwidth & 5 & 3.5 & 5 & 5 & 5 & $\mathrm{MHz}$ \\
\hline Receiver SNR & $\begin{array}{c}\left.\begin{array}{ll}6 & 8.5 \\
11.5 & 15 \\
19 & 21\end{array}\right]^{1}\end{array}$ & 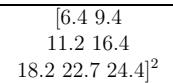 & {$\left[\begin{array}{llll}7 & 5.5 & 7\end{array}\right]^{3}$} & \begin{tabular}{c}
\multicolumn{1}{c}{$\left.\begin{array}{lll}-3.1 & 0.1 \\
& 3.4 & 6 \\
7.1 & 9.6 & 15.6\end{array}\right]^{4}$}
\end{tabular} & 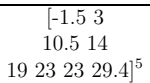 & $\mathrm{dB}$ \\
\hline Number of used subcarriers & 360 & 201 & 1 & 1 & 301 & - \\
\hline Number of total subcarriers & 512 & 256 & 1 & 1 & 512 & $=$ \\
\hline Noise figure of mobile station & 7 & 4.6 & 8 & 9 & 8 & $\mathrm{~dB}$ \\
\hline Implementation loss of mobile station & 2 & 0 & 0 & 0 & 0 & $\mathrm{~dB}$ \\
\hline Processing gain & - & - & {$\left[\begin{array}{llll}25.0 & 17.8 & 10.0\end{array}\right]^{3}$} & 12 & - & $\mathrm{dB}$ \\
\hline Control overhead & - & - & 0.25 & 0.25 & - & - \\
\hline Target load & - & - & 0.75 & 0.875 & - & - \\
\hline Max. number of users & E & E- & {$\left[\begin{array}{llll}6 & 4 & 16 & 4\end{array}\right]^{3}$} & 75 & E- & E- \\
\hline Duplexing & TDD & TDD & TDD & TDD & TDD & E- \\
\hline Building penetration loss [46] & 8.1 & 8.1 & 8.1 & 8.1 & 8.1 & $\mathrm{~dB}$ \\
\hline
\end{tabular}

(1) [1/2 QPSK, 3/4 QPSK, 1/2 16-QAM, 3/4 16-QAM, 2/3 64-QAM, 3/4 64-QAM],

(2) [1/2 BPSK, $1 / 2$ QPSK, 3/4 QPSK, $1 / 2$ 16-QAM, 3/4 16-QAM, 2/3 64-QAM, 3/4 64-QAM]

(3) Services: [AMR 12.2 Voice, PS 64 Data, PS 384 Data]

(4) [1/4 QPSK, $1 / 2$ QPSK, 3/4 QPSK, 3/4 8-QAM, 1/2 16-QAM, 3/4 16-QAM, 3/4 64-QAM]

(5) [1/3 QPSK, $1 / 2$ QPSK, 2/3 QPSK, 1/2 16-QAM, 2/3 16-QAM, 1/2 64-QAM, 2/3 64-QAM] [47]

Table 2: Link budget parameters for considered technologies.

\begin{tabular}{|l|c|c|}
\hline Parameter & Value & Unit \\
\hline Area type & Suburban & - \\
\hline Number of sectors $n_{\text {sector }}$ & 3 & - \\
\hline Height of base station $h_{B S}$ & 30 & $\mathrm{~m}$ \\
\hline Height of mobile station $h_{M S}$ & 1.5 & $\mathrm{~m}$ \\
\hline Coverage requirement & $90 \%$ & - \\
\hline Path loss model & Erceg C & - \\
\hline Shadowing margin & 13.2 & $\mathrm{~dB}$ \\
\hline
\end{tabular}

Table 3: Configuration table under consideration. 


\begin{tabular}{|l|c|c|c|}
\hline $\mathbf{1 x 1}$ SISO & $\begin{array}{c}\text { Mobile } \\
\text { WiMAX }\end{array}$ & HSPA & LTE \\
\hline Bit rate $[\mathrm{Mbps}]$ & 1.4 & 1.5 & 1.2 \\
\hline Range $[\mathrm{m}]$ & 301.7 & 221.4 & 346.3 \\
\hline Power consumption $[\mathrm{W}]$ & 1279.1 & 1672.6 & 1672.6 \\
\hline$P C_{\text {area }}\left[\mathrm{mW} / \mathrm{m}^{2}\right]$ & 4.5 & 10.9 & 4.4 \\
\hline \hline 2x2 MIMO & $\begin{array}{c}\text { Mobile } \\
\text { WiMAX }\end{array}$ & HSPA & LTE \\
\hline Bit rate $[\mathrm{Mbps}]$ & 1.4 & 1.5 & 1.2 \\
\hline Range $[\mathrm{m}]$ & 434.0 & 318.5 & 498.1 \\
\hline Power consumption $[\mathrm{W}]$ & 1689.5 & 2669.0 & 2669.0 \\
\hline$P C_{\text {area }}\left[\mathrm{mW} / \mathrm{m}^{2}\right]$ & 2.9 & 8.4 & 3.4 \\
\hline
\end{tabular}

Table 4: Comparison of the wireless technologies for SISO and 2x2 MIMO

\begin{tabular}{|l|c|c|c|c|c|}
\hline 1x1 SISO & $\begin{array}{c}\text { Mobile } \\
\text { WiMAX }\end{array}$ & $\begin{array}{c}\text { Fixed } \\
\text { WiMAX }\end{array}$ & UMTS & HSPA & LTE \\
\hline Total power consumption $[\mathrm{kW}]$ & 450.5 & 389.1 & 330.1 & 224.1 & 101.3 \\
\hline$f_{\text {cov }}$ & $94.6 \%$ & $95.0 \%$ & $96.5 \%$ & $95.1 \%$ & $97.8 \%$ \\
\hline$f_{\text {pow }}$ & $58.0 \%$ & $63.7 \%$ & $76.4 \%$ & $64.6 \%$ & $84.0 \%$ \\
\hline$f_{\text {tot }}$ & 335.5 & 413.4 & 478.5 & 418.1 & 518.0 \\
\hline Number of used sites & 354 & 306 & 200 & 301 & 135 \\
\hline$P C_{\text {area }}\left[\mathrm{mW} / \mathrm{m}^{2}\right]$ & 3.2 & 2.7 & 2.3 & 1.6 & 0.7 \\
\hline \hline$\underline{\mathbf{2 x 2} \text { MIMO }}$ & Mobile & Fixed & UMTS & HSPA & LTE \\
\hline Total power consumption $[\mathrm{kW}]$ & 377.8 & - & - & 215.1 & 90.7 \\
\hline$f_{\text {cov }}$ & $96.2 \%$ & - & - & $96.2 \%$ & $97.4 \%$ \\
\hline$f_{\text {pow }}$ & $71.6 \%$ & - & - & $70.8 \%$ & $87.7 \%$ \\
\hline$f_{\text {tot }}$ & 454.3 & - & - & 450.2 & 535.8 \\
\hline Number of used sites & 239 & - & - & 249 & 104 \\
\hline$P C_{\text {area }}\left[\mathrm{mW} / \mathrm{m}^{2}\right]$ & 2.6 & - & - & 1.5 & 0.6 \\
\hline
\end{tabular}

Table 5: Comparison of the wireless technologies for the coverage of Brussels. 


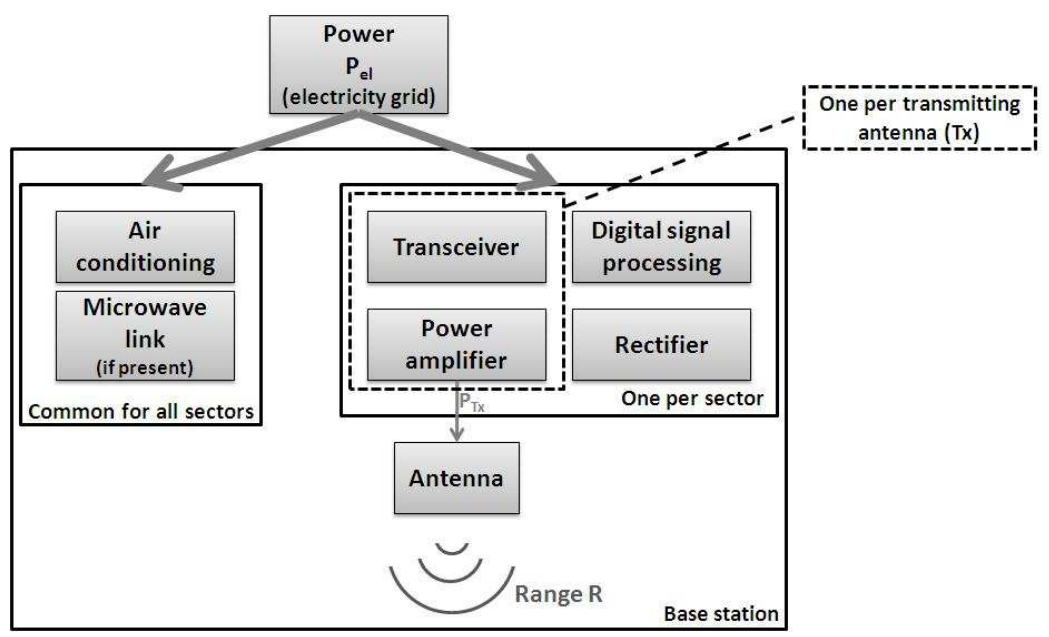

Figure 1: Block diagram of the base station equipment.

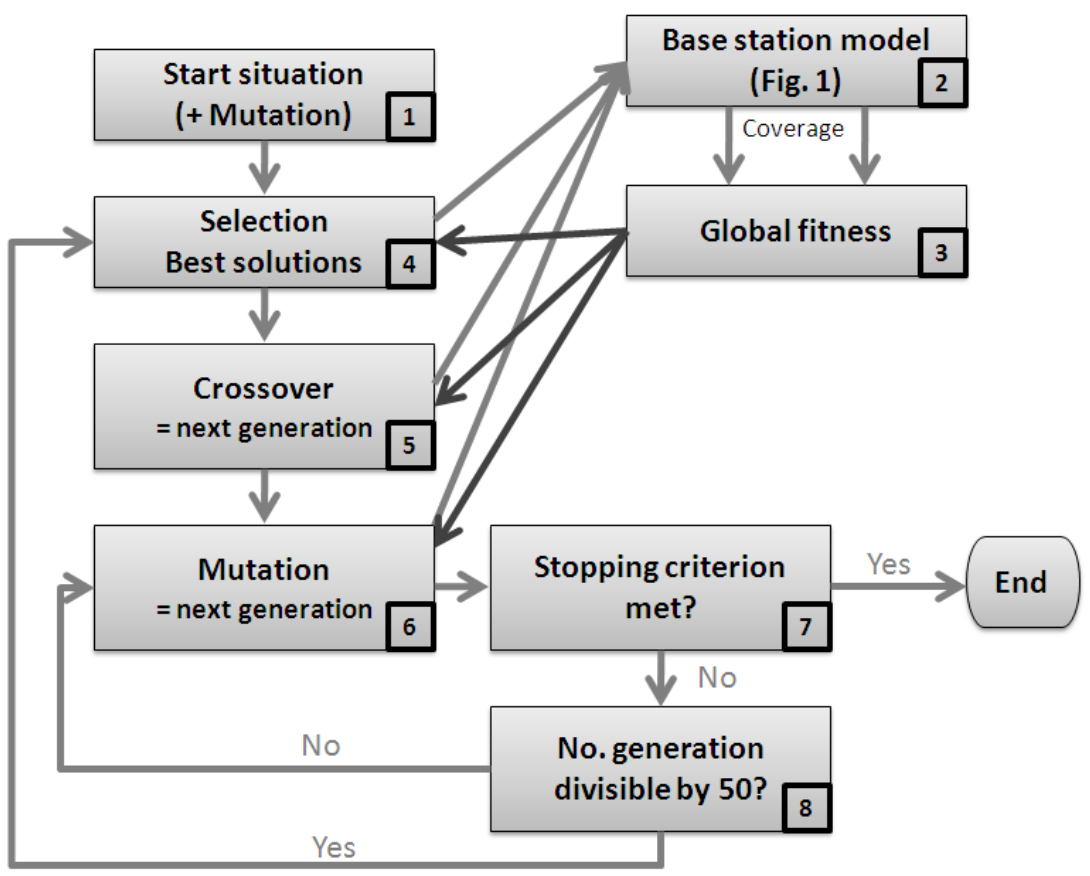

Figure 2: Flow chart of the algorithm. 


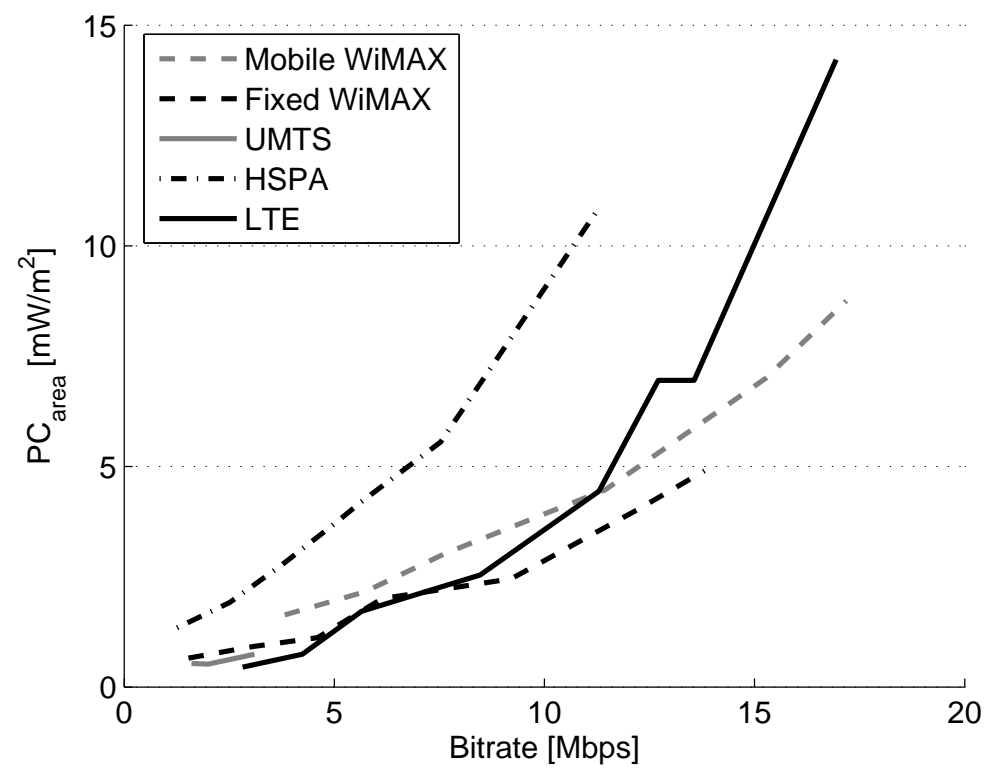

Figure 3: Comparison of the technologies.

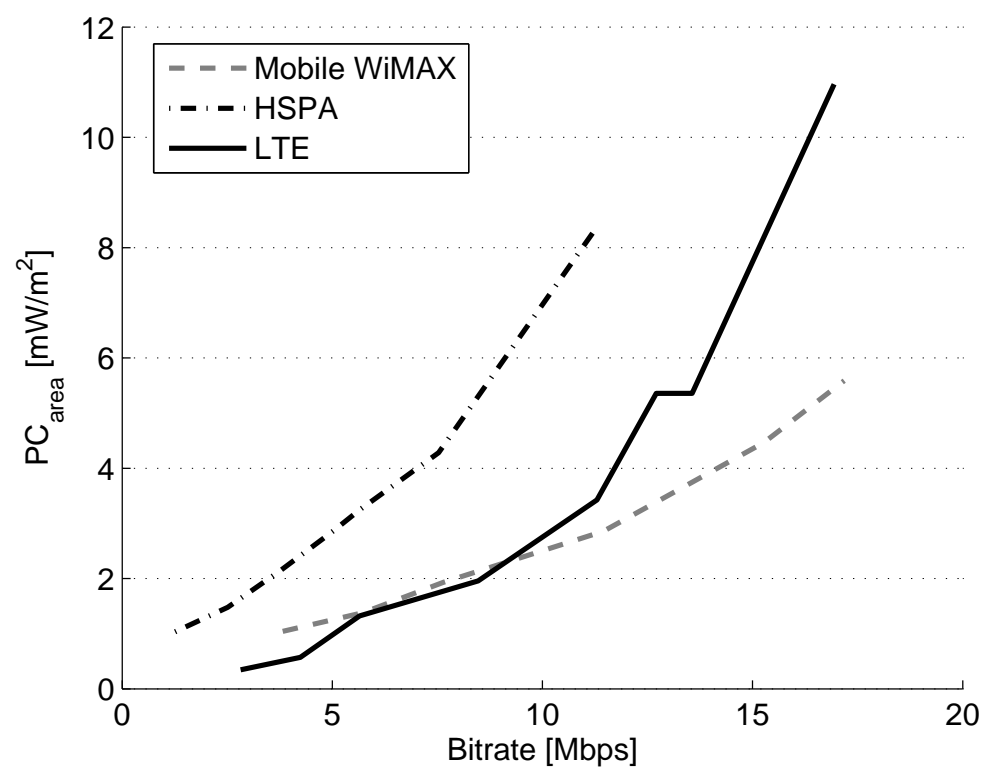

Figure 4: Comparison of mobile WiMAX, HSPA and LTE for a 2x2 MIMO system. 


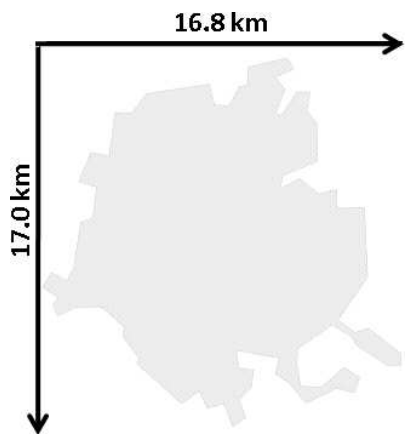

(a)

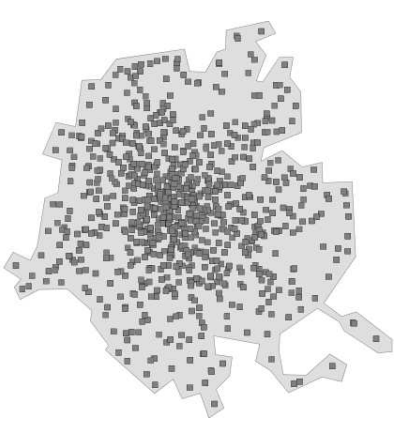

(b)

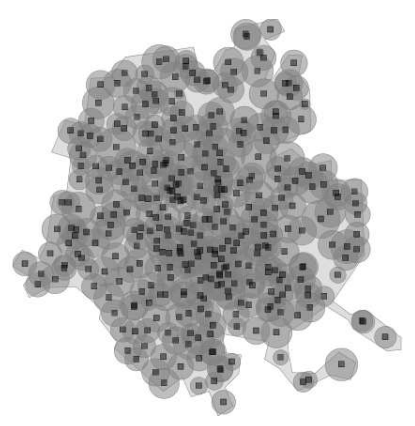

(c)

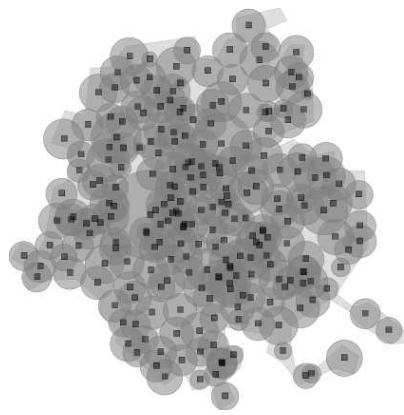

(f)

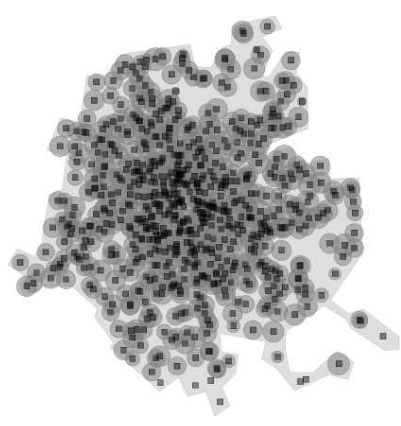

(d)

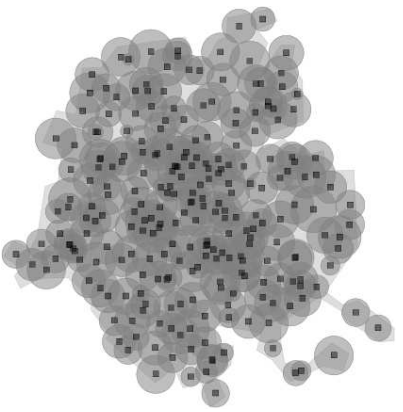

(g)

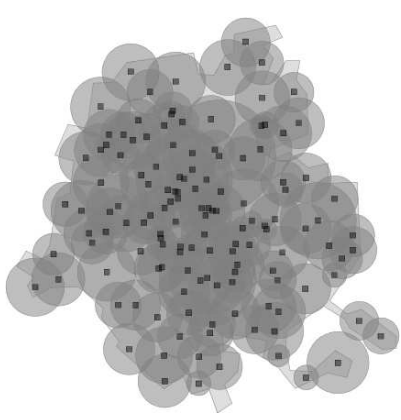

(e)

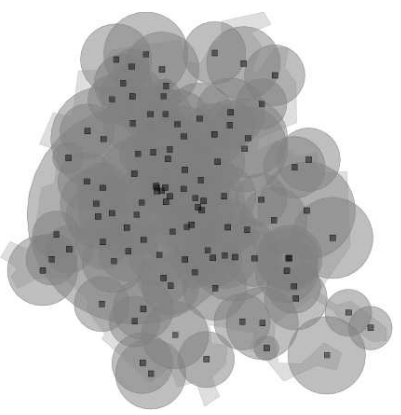

(h)

Figure 5: The area to be covered (a), the sites available in this area (b) and the most energy-efficient network for mobile WiMAX SISO (c), HSPA SISO (d), LTE SISO (e), mobile WiMAX 2x2 MIMO (f), HSPA 2x2 MIMO (g) and LTE 2x2 MIMO (h). 